\title{
Polyphenolic content and antioxidant capacity of white, green, black, and herbal teas: a kinetic study
}

\author{
Shannon, E., Jaiswal, A.K. and *Abu-Ghannam, N. \\ Dublin Institute of Technology, School of Food Science and Environmental Health, College of Sciences and \\ Health, Cathal Brugha Street, Dublin, D01 HV58, Rep. of Ireland
}

\author{
Article history: \\ Received: 12 July 2017 \\ Received in revised form: 3 \\ August 2017 \\ Accepted: 4 August 2017 \\ Available Online: 9 August \\ 2017
}

Keywords:

Camellia sinensis,

White tea,

Herbal tea,

Phenolic compounds,

Antioxidants,

Kinetic modelling

DOI:

https://doi.org/10.26656/fr.2017.2(1).117

\begin{abstract}
Camellia sinensis teas, and tisanes derived from herbs or fruit, are rich in polyphenolic, antioxidant compounds. This study compared the total phenolic content (TPC), total flavonoid content (TFC), ferric reducing antioxidant power (FRAP), DPPH radical scavenging capacity, and caffeine content of teas (black, green, white, chamomile, and mixed berry/hibiscus) over a range of infusion times $(0.5-10 \mathrm{mins})$ at $90^{\circ} \mathrm{C}$. Green, followed by black tea, respectively, had the greatest TPC (557.58 and 499.19 $\mu \mathrm{g} \mathrm{GAE} / \mathrm{g}$ ),

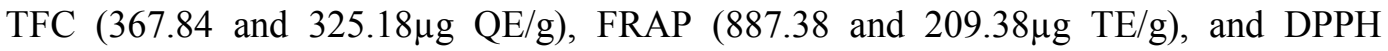
radical scavenging capacity (1233.03 and $866.39 \mu \mathrm{g}$ AAE/g). Caffeine content per cup $(200 \mathrm{~mL})$ in black, green, and white tea was 63,51 , and $49 \mathrm{mg}$ respectively. Changes in the phenolic content and antioxidant capacity of teas were modelled using zero, first, and fractional-conversion-first-order (FCFO) kinetic models. Results fitted a FCFO kinetic model, providing useful data for maximum phytochemical preservation in the optimisation of industrial and domestic processing. As a dietary comparison, green, black, and white tea were found to have a greater phenolic content and antioxidant capacity than fresh orange and apple juice. It can be concluded that green and black teas are significant sources of dietary phenolic antioxidants.
\end{abstract}

\section{Introduction}

Tea is consumed more than any other beverage worldwide (Ho et al., 2008). It is a hot water infusion of the dried, young leaves and/or buds of the evergreen Camellia sinensis plant. Infusions made from other plants such as herbs, berries, or flowers are known as tisanes (Chu and Juneja, 1997; Saberi, 2010). In 2012, 4.884 million tonnes of tea was produced and consumed globally. Per capita, Turkey is the greatest consumer of tea globally, where $3.157 \mathrm{~kg}$ was consumed per person in 2011; followed by Ireland, where $2.191 \mathrm{~kg} /$ per capita was consumed (Caballero et al., 2015). Epidemiological studies strongly suggest that regular consumption of plant polyphenols, such as those found in tea and tisanes, can protect against the development of disorders caused by free radical damage, including cardiovascular disease, cancer, diabetes, osteoporosis, and neurodegenerative diseases (Jung and Ellis, 2001; Duthie, 2007; Pandey and Rizvi, 2009; Dai and Mumper, 2010). There are numerous phytochemicals in teas produced from the $C$. sinensis plant, but polyphenols and the sub-division of flavonoids are considered most important in terms of health benefits due to their ability to act as antioxidants by donating electrons or hydrogen protons to reactive oxygen or nitrogen species. Chamomile and berry/ hibiscus tisanes also contain polyphenols that are considered beneficial to health, but at significantly lower levels than $C$. sinensis derived teas. The principle polyphenols in chamomile are chrysin, luteolin, and coumarins (Igile et al., 1994; Yang et al., 2008). The berry/hibiscus tisane used in this study contains procyanidins, rutin, anthocyanins, resveratrol, $\beta$ carotene, ellagic acid, and the xanthophyll, lutein (Petronilho et al., 2012; Guimarães et al., 2013; Juneja et al., 2013).

Water temperatures and infusion times used for tea brewing vary greatly, and have a significant effect on the extraction yield of phytochemicals such as polyphenolic compounds; and methylxanthines - for example, caffeine, theophylline, and theobromine. Domestic 
temperatures generally range from $65-95^{\circ} \mathrm{C}$, with green and white teas commonly brewed at lower temperatures than black varieties. Some studies have shown that increased polyphenolic content of black, green, and white $C$. sinensis teas can be achieved with brewing times in excess of ten minutes (Langley-Evans, 2000; Astill et al., 2001; Komes et al., 2010; Imran et al., 2013). However, this is primarily for extraction of compounds in industrial applications, since astringency and bitterness also increase with time, affecting organoleptic properties of the beverage (Brown, 2014). Loose leaf versus bagged, or powdered tea, and the material from which the bag is made can influence the rate of phytochemical extraction. Variables such as cultivar, ontogenetic factors, geographic location, processing conditions, storage, and particle size, or grade, of tea leaves also influence the phytochemical composition of the beverage (Astill et al., 2001; Samaniego-Sánchez et al., 2011; Brown, 2014; Lee et al., 2015). Kinetic modelling of antioxidant behaviour in food and beverage matrices has provided useful data for the optimisation of phytochemical extraction (Rao et al., 2014). An understanding of the kinetics of phenolic and antioxidant degradation in tea as a function of infusion time may be used to optimise industrial and domestic brewing processes for maximum phytochemical preservation.

Some studies have evaluated the kinetics of solidliquid extraction of antioxidants in green or black tea (Anissi et al., 2014; Ahmad et al., 2015; Fernando and Soysa, 2015), however there is a void in the literature on kinetic data regarding white and herbal teas in comparison to green and black varieties. The present study focused on quantification and comparison of the total phenolic content, total flavonoid content, caffeine content, ferric reducing antioxidant power, and DPPH radical scavenging capacity of a range of commercial teas (black, white, green, chamomile, and mixed berry/ hibiscus) over a range of infusion times (0.5-10 mins), using an average domestic brewing temperature $\left(90^{\circ} \mathrm{C}\right)$. As a dietary comparison, the antioxidant and phenolic content of each tea was also compared to that of fresh orange and apple juice. In addition, a kinetic study was carried out over a range of infusion times to determine the rate at which maximum antioxidants are lixiviated from each tea. Based on the findings, an optimum infusion time for antioxidant-rich tea is recommended.

\section{Materials and methods}

\subsection{Samples}

Black, green, chamomile, and berry/hibiscus teas were prepared from Barry's Tea brand, while white tea samples were prepared from $Q i$ brand tea bags. All samples were purchased from local supermarkets in Dublin during September 2013. All chemicals were purchased from Sigma-Aldrich, Ireland unless otherwise indicated.

\subsection{Sample preparation}

After an initial study, a brewing time of 0.5 to 10 minutes was used to infuse each tea type at a mean, domestic brewing temperature of $90^{\circ} \mathrm{C}$. Boiled, potable tap water $\left(100^{\circ} \mathrm{C}, 200 \mathrm{~mL}\right)(\mathrm{GH}$ Zeal Ltd L0132 glass thermometer, U.K.) was transferred to a pre-heated ceramic cup. The infusion water was found to have a mean temperature of $90^{\circ} \mathrm{C}$ after transfer to the cup. One tea bag (mean dry leaf mass $\sim 2.0 \mathrm{~g}$ ) was added and stirred $\left(360^{\circ}\right.$ twice) with a glass rod. After 0.5 mins, a stainless steel, manual tea bag squeezer (Kitchen Craft leXpress, U.K.) was used to squeeze $(3 \mathrm{sec})$ and discard the bag. The brewed tea was chilled on ice and stored, away from light, at $4^{\circ} \mathrm{C}$ (Lec AC150, U.K.). The process was repeated with a fresh tea bag in quadruplicate for each infusion time.

\subsection{Determination of total polyphenolic content (TPC)}

TPC was carried out according to existing protocols in the laboratory as described by Rajauria et al. (2013) using the Folin Ciocalteu assay. In a 96-well microtiter plate, $2 \%$ sodium carbonate $(2 \mathrm{~mL})$ was added to each tea sample $(100 \mu \mathrm{L})$. After 2 mins, $50 \%$ Folin Ciocalteu reagent $(100 \mu \mathrm{L})$ was added. After 30 mins incubation at $25^{\circ} \mathrm{C}$, protected from light, absorbances were measured at $720 \mathrm{~nm}$ using a UV-Vis spectrophotometric microplate reader (BioTek PowerWave, Gen5 Data Analysis, USA). Results were expressed in gallic acid equivalents per gram of dry tea $(\mathrm{GAE} / \mathrm{g})$ extrapolated from a calibration curve of gallic acid $(0-500 \mu \mathrm{g} / \mathrm{mL})$.

\subsection{Determination of total flavonoid content (TFC)}

The aluminium chloride assay described by Jaiswal et al. (2012) was used to quantify the TFC of each tea. Briefly, each tea sample $(250 \mu \mathrm{L}), \mathrm{ddH}_{2} \mathrm{O}(1.25 \mathrm{~mL})$ and $5 \%$ sodium nitrite $(75 \mu \mathrm{L})$ were added. After 6 mins, $10 \%$ aluminium chloride solution $(150 \mu \mathrm{L})$ was added. Sodium hydroxide (1M $0.5 \mathrm{~mL}$; Fluka, Ireland) and $\mathrm{ddH}_{2} \mathrm{O}(575 \mu \mathrm{L})$ was added to bring the total volume to $2.5 \mathrm{~mL}$. A blank was prepared in the same manner, using $\mathrm{ddH}_{2} \mathrm{O}(250 \mu \mathrm{L})$. Absorbances were read at $510 \mathrm{~nm}$. Results were expressed in quercetin equivalents per gram $(\mathrm{QE} / \mathrm{g})$ of dry tea, through a calibration curve of quercetin $(0-100 \mu \mathrm{g} / \mathrm{mL})$. 
2.5 Determination of ferric reducing antioxidant power (FRAP)

The ferric reducing antioxidant power assay (Benzie and Strain, 1996) was used to determine antioxidant capacity. FRAP reagent was prepared $(300 \mathrm{mM}$ sodium acetate buffer, $\mathrm{pH}$ 3.6, $20 \mathrm{mM}$ ferric chloride hexahydrate $\left(\mathrm{FeCl}_{3} \cdot 6 \mathrm{H}_{2} \mathrm{O}\right)$, and $10 \mathrm{mM}$ 2,4,6-Tris(2pyridyl) s-triazine, Fluka, Ireland; in $40 \mathrm{mM} \mathrm{HCl}$, Fisher -Scientific, Ireland, in a ratio of $10: 1: 1, \mathrm{v} / \mathrm{v} / \mathrm{v}$ ) and incubated in a water bath at $37^{\circ} \mathrm{C}$ for 5 mins. In a microtiter plate, FRAP reagent $(100 \mu \mathrm{L})$ was added to each tea sample $(50 \mu \mathrm{L})$. A blank was prepared in the same manner, using $\mathrm{ddH}_{2} \mathrm{O}(50 \mu \mathrm{L})$ in place of the tea sample. After 10 mins incubation at $25^{\circ} \mathrm{C}$, the absorbance was measured at $593 \mathrm{~nm}$. Results were expressed in Trolox equivalents per gram (TE/g) of dry tea, extrapolated from a calibration curve of Trolox $(0-25$ $\mu \mathrm{g} / \mathrm{mL})$.

\subsection{Determination of 2,2-diphenyl-1-picrylhydrazyl radical scavenging capacity}

The antioxidant capacity of each tea was determined using the DPPH radical scavenging capacity assay according to Blois (1958). DPPH radical solution (165 $\mu \mathrm{M}$, in methanol) or $\mathrm{ddH}_{2} \mathrm{O}$ was added to each tea. After 30 mins incubation in darkness at $30^{\circ} \mathrm{C}$, absorbances were measured at $517 \mathrm{~nm}$. DPPH radical scavenging capacity was calculated as follows:

$\%$ scavenging capacity $=[($ Abs Control $)-($ Abs tea $)$ (Abs Control) $]^{*} 100$

DPPH radical scavenging capacity was expressed in ascorbic acid equivalents per gram of dry tea (AAE/g), extrapolated from a calibration curve of L-ascorbic acid $(0-12 \mu \mathrm{g} / \mathrm{mL})$

\subsection{Determination of caffeine content}

Reverse phase high performance liquid chromatography was used to quantify caffeine (AllianceWaters e2695 Separations Module, USA), using a C18 reverse phase column (Waters Atlantis T3, 250 x 4.6mm $\mathrm{x} \mathrm{mm}, 5 \mu \mathrm{m}$ particle size, USA), and a UV photodiode array detector (Waters 2998, USA). Tea samples were syringe-filtered (Millex Durapore PVDF, $0.22 \mu \mathrm{m}$ pore) into HPLC vials. Two mobile phases were used in a gradient programme for 70 mins at $25^{\circ} \mathrm{C}$ : sodium acetate $(2 \mathrm{mM})$ with acetic acid (6\%); and acetonitrile (100\%; Fluka, Ireland). Mobile phases were filtered (Merck Millipore HVLP $0.45 \mu \mathrm{m}$ filter, Germany) and sonicated (Branson Ultrasonic 5510, USA). Injection volume was $20 \mu \mathrm{L}$, with a flow rate of $1 \mathrm{~mL} / \mathrm{min}$. Analyses were carried out in quadruplicate. Detection was performed at $280 \mathrm{~nm}$. The concentration of caffeine in the tea samples was extrapolated from a calibration curve of caffeine ( 25 $-200 \mu \mathrm{g} / \mathrm{mL}$ ).

\subsection{Kinetic study}

The kinetics of tea phenolic content, flavonoid content and antioxidant capacity were described by fitting a zero order (Equation 1), first-order (Equation 2), and fractional conversion first-order (FCFO) (Equation 3) to the experimental data.

$$
\begin{aligned}
& \mathrm{A}=\mathrm{A}_{0} \pm k \mathrm{t} \\
& \mathrm{A}=\mathrm{A}_{0} * \exp \pm k \mathrm{t} \\
& \mathrm{A}=\mathrm{A}_{\text {eq }}+\left(\mathrm{A}_{0}-\mathrm{A}_{\mathrm{eq}}\right) /(\exp \pm k \mathrm{t})
\end{aligned}
$$

Where $\mathrm{A}$ is the parameter to be estimated, the sub index 0 indicates the initial value of the parameter (absorbance value of tea at $0.5 \mathrm{mins}$ ), $t$ is the infusion time, and $k$ is the rate constant at temperature $t$. The sub index, eq, indicates equilibrium value (final absorbance value of tea at 10 mins). For the parameter estimation, the individual measured concentrations were used instead of mean values of quadruplicate experiments, thus taking into account variability within the samples. The coefficient of determination $\left(\mathrm{R}^{2}\right)$ and mean square error (MSE) were used as criteria for adequacy of fit.

\subsection{Statistical analysis}

Statgraphics Centurion XVII was used for kinetic modelling and statistical analyses, with differences considered significant where $P \leq 0.05$. All experiments were conducted in quadruplicate $(n=4)$ and replicated at least twice. Results were calculated as mean values \pm standard deviation. Fisher's Least Significant Difference (LSD) procedure was used to discriminate amongst the means of the variables.

\section{Results and discussion}

All polyphenolic content and antioxidant capacity values are presented for teas after 5 mins infusion, rather than after the maximum infusion time (10 mins). Five minutes was determined to be the optimum brewing time, as no significant $(\mathrm{P}>0.05)$ increase was found in the phytochemical content between 5 and 10 mins for all tea varieties investigated in this study. Figure 1 shows the comparative TPC, TFC, FRAP, and DPPH radical scavenging capacity of black, green, white, chamomile, and berry teas after 5 mins infusion. 


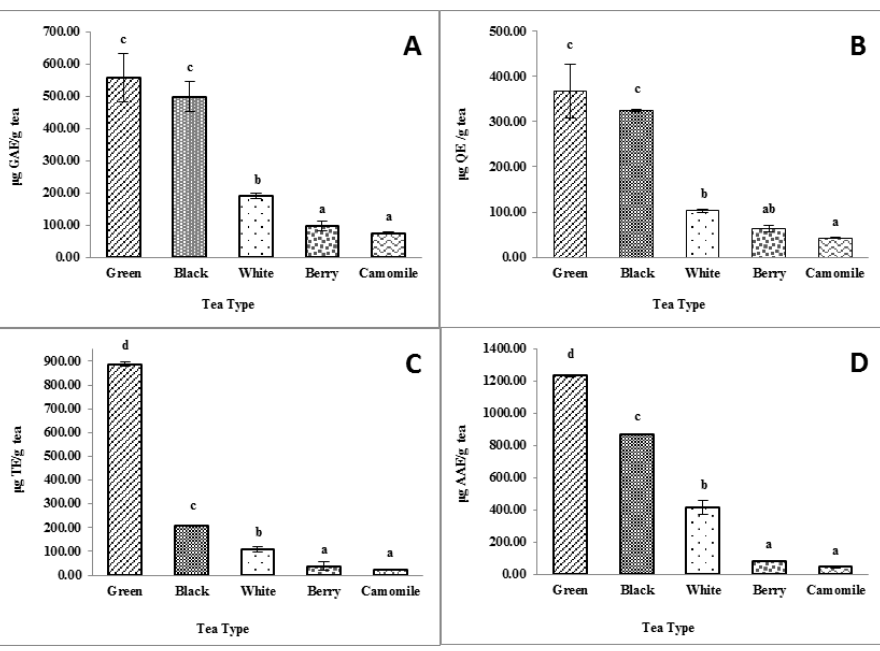

Figure 1. Comparative TPC (A), TFC (B), FRAP (C), and DPPH radical scavenging capacity (D) of black, green, white, chamomile, and berry teas after $5 \mathrm{~min}$ infusion. Values are the mean of four replicates for each tea type \pm standard deviation. Letters denote least significant difference between columns $(P$ $\leq 0.05)$

\subsection{Total polyphenolic content}

After five minutes infusion, green tea had the highest total phenolic content of $557.58 \pm 74.98$; followed by black $499.19 \pm 46.56$; white $190.24 \pm 7.73$; berry $98.86 \pm$ 14.72; and chamomile $75.31 \pm 3.65 \mu \mathrm{g}$ GAE/g tea. No published results are available for the TPC, or any phytochemical content, of the specific Barry's and $Q i$ brands of teas used in this study. Reported TPC results for similar teas prepared under comparable brewing conditions vary widely. Adjusting for differences in infusion volume and time, Unachukwu et al. (2010) quantified a TPC of $1.17 \mathrm{mg}$ GAE/g in green tea; and $0.96 \mathrm{mg} \mathrm{GAE} / \mathrm{g}$ in white tea. Yoo et al. (2008) found a TPC of $0.746 \mathrm{mg}$ GAE/g in black tea, and $0.84 \mathrm{mg}$ GAE/ $\mathrm{g}$ in chamomile tea. Achoribo et al. (2012) reported 0.65 $\mathrm{mg} \mathrm{GAE} / \mathrm{g}$ for a hibiscus-based tea. As expected from published values, green tea was found to have the highest level of total phenolics (Komes et al., 2010; Anissi et al., 2014), followed by black tea; while the chamomile, berry, and white teas were significantly lower $(\mathrm{P} \leq 0.05)$. White tea, although from the same $C$. sinensis plant as black and green varieties, may have a lower TPC due to the fact that oxidation by polyphenol oxidase is prevented in white tea processing (Astorino et al., 2012). Therefore, the phenolic monomers in the fresh leaves are not complexed into polyphenols such as catechins in green tea, or thearubigins in black tea. Rusak et al. (2008) reported that the extraction of total phenolics from white tea leaves occurred at a significantly slower rate than that of other teas. Their study found that although the highest TPC of both white and green teas was established after 30 mins extraction, green tea reached a significantly higher TPC, particularly flavonoids, within the first 5 mins of extraction. The filamentous trichomes covering the buds from which white tea is prepared to have a lipophilic cuticle surrounding their cell walls (Rusak et al., 2008) which may affect the migration kinetic of hydrophilic catechins during water-infusion.

\subsection{Total flavonoid content}

After 5 mins infusion, green tea had the highest total flavonoid content of $367.84 \pm 59.61 \mu \mathrm{g} Q \mathrm{QE} / \mathrm{g}$ tea. Adjusting for differences in infusion volume and time, published results for comparable TFC experiments have been reported as $1640 \mu \mathrm{g} \mathrm{QE} / \mathrm{g}$ for green tea and $1480 \mu \mathrm{g}$ QE/g for black tea (Oh et al., 2013). A mean TPC of $183,000 \mu \mathrm{g}$ QE/g was reported in a range of chamomile teas by Haghi et al. (2013) and $87.17 \mu \mathrm{g} \mathrm{QE} / \mathrm{g}$ in a hibiscus-based tea (Achoribo et al., 2012). No results have been reported in quercetin equivalents for white tea, however, Carloni et al. (2013) quantified a TFC of 3900 $\mu \mathrm{g}$ catechin equivalents/g in white tea using the same methodology as the present study. The total flavonoid content of $C$. sinensis and herbal teas was lower than most published values. However, a direct comparison may not be equivalent due to the varying geographic locations, harvesting time, and environmental conditions from which each study selected samples, and the impact this has on phytochemical content.

\subsection{Ferric reducing antioxidant power}

After 5 mins infusion, green tea the highest ferric reducing power of $887.38 \pm 8.71$, followed by black $209.38 \pm 1.86$; white $110.43 \pm 11.85$; berry $37.96 \pm$ 17.42; and chamomile $24.57 \pm 1.26 \mu \mathrm{g} \mathrm{TE} / \mathrm{g}$ tea. Reported FRAP results for similar teas prepared under comparable brewing conditions vary. Allowing for differences in mass of dry tea and infusion time, Rusak et al. (2008) reported $1.05 \mathrm{mmol} \mathrm{TE} / \mathrm{L}$ (approximately equivalent to $5250 \mu \mathrm{g} \mathrm{TE} / \mathrm{g}$ ) in green tea. Prior and Cao (1999) quantified $8.31 \mu \mathrm{mol} \mathrm{TE} / \mathrm{mL}$ (approximately equivalent to $2077 \mu \mathrm{g} \mathrm{TE} / \mathrm{g}$ ) in black tea. Andlauer and Héritier (2011) found $0.484 \mathrm{mg} \mathrm{TE} / \mathrm{g}$ in white tea. Pellegrini et al. (2003) reported $1.26 \mathrm{mmol} \mathrm{TE} / \mathrm{L}$ in chamomile tea (approximately equivalent to $630 \mu \mathrm{g} \mathrm{TE} /$ g); and $312 \mu \mathrm{mol}$ Trolox equivalents $/ 100 \mathrm{~mL}$ (approximately equivalent to $124 \mu \mathrm{g} \mathrm{TE} / \mathrm{g}$ ) was reported for a hibiscus-based tea (Sáyago-Ayerdi et al., 2007). As expected, green tea had the highest ferric reducing antioxidant power, followed by black, white, berry and chamomile teas. A similar study using FRAP analysis of green and black tea bags infused at $90^{\circ} \mathrm{C}$ for time periods ranging from 0.25 to 15 minutes, found that green tea 
had an antioxidant capacity almost three times higher than that of black tea (Langley-Evans, 2000). This is due to the changes that occur in black tea during processing, catalysed by polyphenol oxidase. The flavanols in the (green) tea leaves are converted to oxyproducts in black tea, such as thearubigins and theaflavins, resulting in a loss of antioxidant capacity (Benzie and Szeto, 1999).

\subsection{2,2-diphenyl-1-picrylhydrazyl radical scavenging capacity}

The same trend observed in TPC, TFC, and FRAP occurred in DPPH radical scavenging capacity, which was greatest in green tea $(1233.03 \pm 7.88 \mu \mathrm{g} \mathrm{AAE} / \mathrm{g})$; followed by black $866.39 \pm 2.97$; white $414.03 \pm 44.22$; berry $82.89 \pm 6.13$; and lowest in chamomile (47.44 \pm $1.04 \mu \mathrm{g} \mathrm{AAE} / \mathrm{g}$ ). Reported DPPH radical scavenging capacity for similar teas prepared under comparable brewing conditions vary widely. Allowing for differences in mass of dry tea and infusion time, Oh et al. (2013) found green tea to have a DPPH radical scavenging capacity of $12,390 \mu \mathrm{g}$ AAE/g and $9890 \mu \mathrm{g}$ AAE/g in black tea. Karori et al. (2007) reported 1900 $\mu \mathrm{g} \mathrm{AAE} / \mathrm{g}$ in white tea, while two similar studies found $110 \mu \mathrm{g}$ AAE/g in chamomile (Sazegar et al., 2011); and $639 \mu \mathrm{g} \mathrm{AAE} / \mathrm{g}$ in a hibiscus tea (Ramadan-Hassanien, 2008).

The observed TPC, TFC, FRAP, and DPPH results for each tea in the present study may differ to some published values due to differences in tea cultivar, soil type, altitude of cultivation, post-harvest storage, processing conditions, and ontogenetic effects ( Imran et al., 2013; Pavlović et al., 2013; Yang and Liu, 2013; Lee et al., 2015; Soni et al., 2015).

\subsection{Antioxidant comparison with fresh orange and apple juice}

\subsubsection{TPC comparison with teas after 5 min infusion and freshly juiced orange and apple}

As a dietary comparison, the total phenolic content of two commonly consumed juices, freshly squeezed orange and apple, was compared to that of each tea. The high proportion of phenolic antioxidant compounds in orange and apple juices and their health benefits have been widely reported (Preedy, 2014; Cuervo et al., 2015; Hui and Evranuz, 2015). The World Health Organization recommends consuming at least five portions of fruit and vegetables per day to reduce the risk of diseases such as cancer, heart disease, and diabetes (WHO, 2015). Considering the significant consumption of tea worldwide, the total phenolic content of each tea was therefore compared to that of the juices as a measure of its dietary antioxidant contribution. TPC was quantified using the same methodology detailed above.

Orange juice was found to have a TPC of $436.6 \pm$ 10.9 , and apple juice $603.33 \pm 14.1 \mu \mathrm{g} \mathrm{GAE} / \mathrm{g}$. None of the five teas had a total phenolic content equal to that of apple juice $(603.33 \mu \mathrm{g} \mathrm{GAE} / \mathrm{g})$. However, green and black teas (557.58 and $499.19 \mu \mathrm{g}$ GAE/g respectively) both had a greater TPC than orange juice (436.6 $\mu \mathrm{g}$ GAE/g). Green tea had $92.42 \%$ the TPC of apple juice, and black tea had $82.74 \%$. White, berry, and chamomile teas $(190.24 \pm 7.73,98.86 \pm 14.72,75.31 \pm 3.65 \mu \mathrm{g}$ $\mathrm{GAE} / \mathrm{g}$ ) had a significantly lower TPC of $31.53 \%$, $16.39 \%$, and $12.48 \%$ respectively, in comparison to apple juice. In comparison to orange juice, white, chamomile, and berry teas had a TPC of $43.57 \%$, $22.64 \%$, and $17.25 \%$ respectively.

Figure 2 shows the comparative total phenolic content, and DPPH radical scavenging capacity of teas after 5 mins infusion, orange, and apple juice in $\mu \mathrm{g}$ $\mathrm{AAE} / \mathrm{g}$.

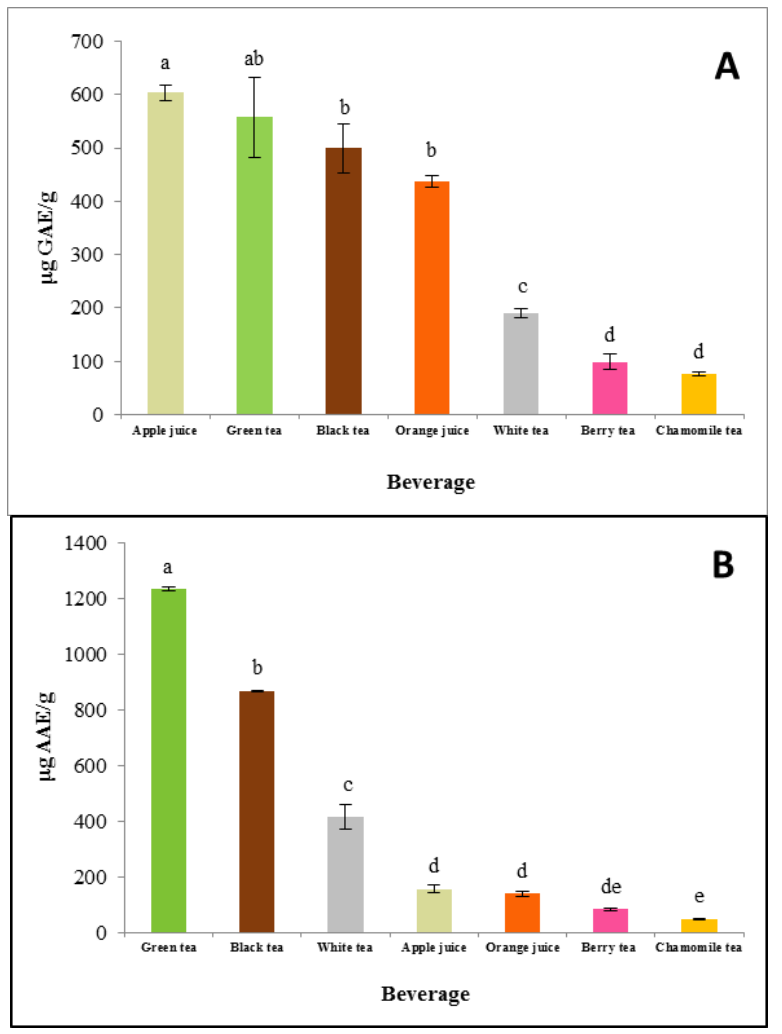

Figure 2. (A) Comparative total phenolic content, and (B) DPPH radical scavenging capacity of teas after $5 \mathrm{~min}$ infusion, orange, and apple juice. Values are the mean of four replicates for each tea type \pm standard deviation. Letters denote least significant difference between columns $(P \leq 0.05)$

\subsubsection{DPPH radical scavenging capacity comparison with teas after 5 min infusion and freshly juiced orange and apple}


As discussed, a comparison may be made between the dietary antioxidant contribution of phenolic antioxidants in orange and apple juices and that of tea. The DPPH radical scavenging capacity of freshly juiced orange and apple was quantified using the same methodology detailed in above. Orange juice was found to have a DPPH radical scavenging capacity of $138.42 \pm$ 10.9, and apple juice $155.41 \pm 14.1 \mu \mathrm{g}$ AAE/g. Green, black, and white teas were found to have DPPH radical scavenging capacities significantly greater $(P \leq 0.05)$ than that of apple juice. As percentage comparisons, green, black, and white tea capacities were $793.41 \%$, $557.49 \%$, and $266.14 \%$ greater than that of apple juice. Berry and chamomile teas had lower DPPH radical scavenging capacities than apple juice: $53.34 \%$ and $30.53 \%$ in comparison. A similar trend was seen in the comparison of the teas to the orange juice. Green, black, and white teas had DPPH radical scavenging capacities $890.79 \%, 625.91 \%$, and $299.11 \%$ greater than the orange juice, while berry and chamomile teas were only $59.88 \%$ and $34.27 \%$ in comparison. From this data, green, black, and white teas have a significantly greater antioxidant capacity than both apple and orange juices per $\mu \mathrm{g}$ ascorbic acid equivalents per gram. This trend is common in published results for comparable DPPH assays (Ramadan-Hassanien, 2008). Paganga et al. (1999) found that two $150 \mathrm{~mL}$ servings of black tea had the same antioxidant activity as four whole apples, seven glasses of long life orange juice, twenty glasses of long life apple juice, or one glass of red wine (each $150 \mathrm{~mL}$ ).

In respect of phenolic antioxidant content, the TPC and DPPH results show that $C$. sinensis teas are comparable to and in several cases greater than, the fruit juices studied. This is due to the presence of flavonoids in $C$. sinensis plants, which comprise $30-40 \%$ of the dry mass of tea leaves (Juneja et al., 2013). The majority of tea flavonoids are flavan-3-ols (or flavanols). Examples include epigallocatechin in green tea, and theaflavin-3gallate, in black tea. They are more potent antioxidants than those found in apples and oranges due to delocalised electrons in their alternating single and double (conjugated) bonds arranged in polyphenolic systems. If an electron from a flavanol molecule is lost to a free radical, the flavanol remains stable due to the sharing of electrons in its conjugated system (Kaur and Kapoor, 2001). For this reason, C. sinensis teas are more powerful dietary antioxidants than most fruits.HPLC analysis of caffeine.

HPLC peaks and retention times for the five tea varieties at each infusion time were compared to those of the caffeine standards. Caffeine content was extrapolated from the standard curve equation generated. HPLC results for caffeine content per $200 \mathrm{~mL}$ serving of tea after 5 mins infusion are presented in Figure 3.

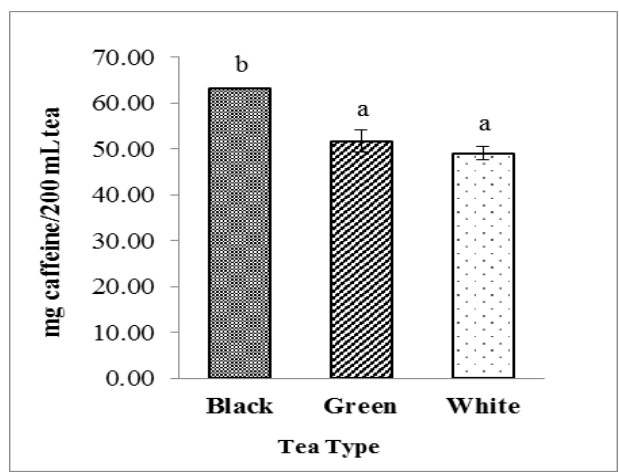

Figure 3. Comparative caffeine content of green, black, and white teas after 5 min infusion. Values are the mean of four replicates for each tea type \pm standard deviation. Letters denote least significant difference between columns $(P \leq 0.05)$

After 5 mins infusion, black tea had the highest caffeine content of $63.3 \pm 0.01$; followed by green $51.7 \pm$ 2.41 ; and white $49.1 \pm 1.39 \mathrm{mg} / 200 \mathrm{~mL}$. These values are in line with those published for black, green, and white teas (Astill et al., 2001; Preedy, 2012). Chin et al. (2008) quantified caffeine contents of 14-61 mg per serving in white (lowest), green, and black teas (highest); and zero caffeine in herbal teas. Carloni et al. (2013) reported $15.6 \mathrm{mg} / 200 \mathrm{~mL}$ in white tea, $36.6 \mathrm{mg} / 200 \mathrm{~mL}$ in green tea, and $32.6 \mathrm{mg} / 200 \mathrm{~mL}$ in black tea after seven minutes infusion. As expected, caffeine was not detected in chamomile or berry teas (Duke, 1997; Ali et al., 2005; Guimarães et al., 2013). In C. sinensis plants, caffeine is biosynthesised by the transfer of the methyl group from S-adenosyl methionine to methyl xanthine. The rate of this synthesis is increased during the withering/warm drying process of tea production (Panda, 2011). It was expected that black tea would have the greatest caffeine content since it is subjected to more withering than green and white teas. Although black, green, and white teas are a source of healthy dietary phenolics and antioxidants, excessive consumption can result in a caffeine intake above recommended levels. In order to avoid the side effects of excess caffeine consumption, such as heart palpitations, insomnia, and anxiety, a maximum of 300 mg caffeine per day is recommended for adults; and less than $200 \mathrm{mg} /$ day during pregnancy (Preedy, 2012). 300 mg equates to approximately five servings of black tea or six servings of green or white tea. In vitro values determined in this study may differ from those in vivo since polyphenols undergo extensive modification during digestion via conjugation in the intestinal cells and liver by sulphation, methylation, and glucuronidation (Setchell et al., 2003). 


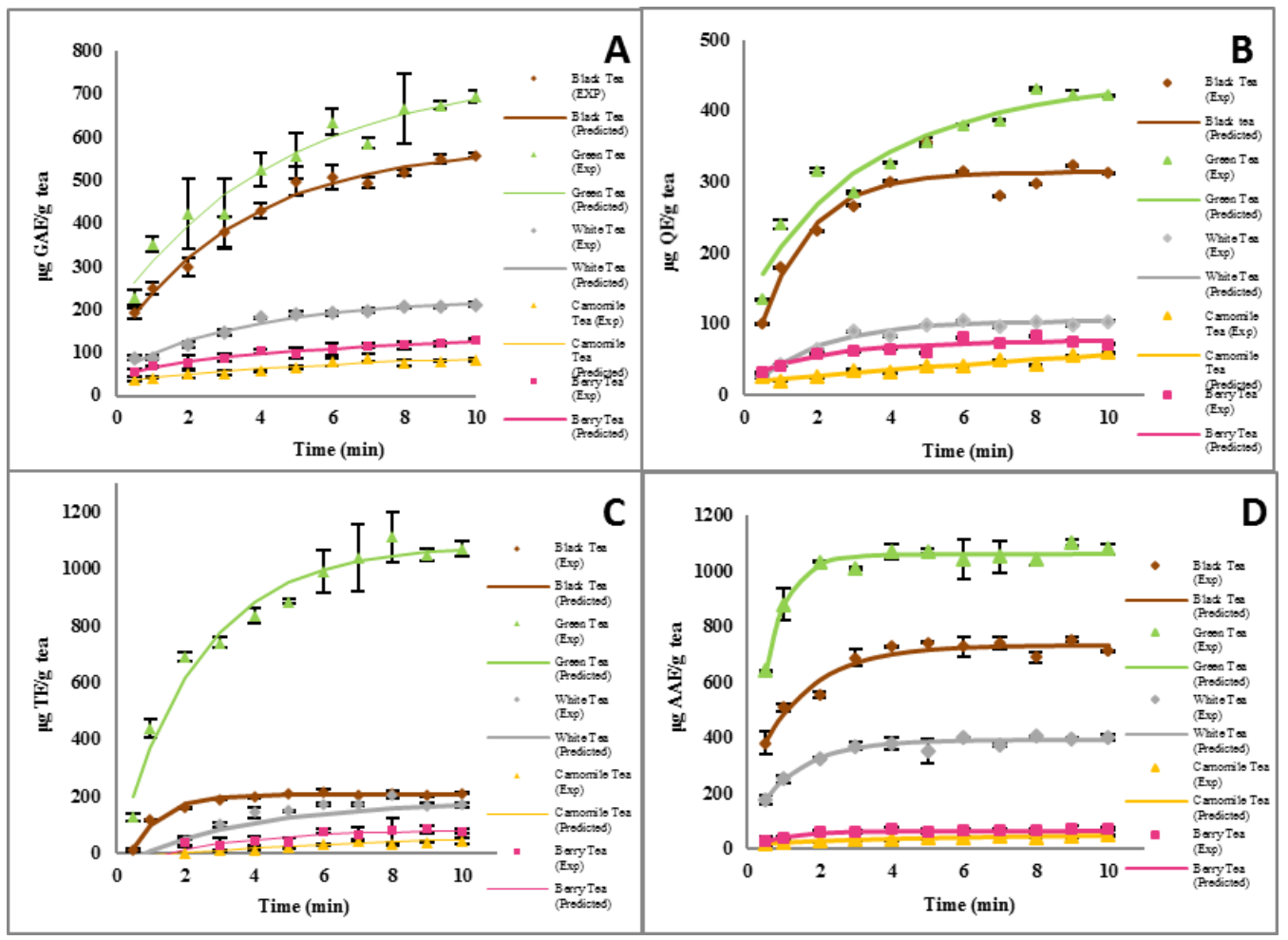

Figure 4. Experimental and predicted data (fractional conversion first order kinetics model) for the effect of infusion time on the TPC (A), TFC (B), FRAP (C), and DPPH radical scavenging capacity (D) of black, green, white, chamomile, and berry teas. Values are the mean of four replicates for each tea type \pm standard deviation.

\subsection{Kinetic study}

A FCFO kinetics model was found to best fit all data, with the highest $\mathrm{R}^{2}$ values, ranging from 77.49 to 98.12, and the lowest MSE value ranging from 0.26 to 5477.91. Kinetic parameter mean estimates, corresponding coefficient of determination, and mean square error of phenolic content and the antioxidant capacity increase in teas after 10 mins infusion are presented in Table 1.

A FCFO model was expected to fit each of the four assays since the raw data clearly demonstrated a steep initial increase, followed by a more constant content (Jaiswal et al., 2012). Experimental and predicted data (FCFO kinetics model) for TPC, TFC, FRAP, and DPPH radical scavenging capacity of teas due to infusion over 10 mins are presented in Figure 4.

Kinetic studies for single tea cultivars have reported optimum infusion times in line with the present study. For example, Fernando and Soysa (2015) investigated the extraction kinetics of phenolic compounds, caffeine, catechins, and antioxidant activity as a function of time in black tea and found the optimum infusion time for the release of tea constituents was $2-8$ mins. However, no kinetic data has been published for the range of teas used in the present study.

Kinetic modelling of phenolic and antioxidant behaviour in tea matrices as a function of infusion time provides useful data for the prediction of organoleptic and nutritional losses and allows for the calculation of TPC, TFC, FRAP, and DPPH radical scavenging capacity in theoretical experiments at untested infusion times. For example, in the case of white tea, application of this model would determine whether a longer infusion time could result in increased phenolic content or antioxidant activity. Kinetic data may be used to optimise industrial and domestic brewing processes for maximum phytochemical and nutritional preservation.

\section{Conclusion}

Green, followed by black tea, had the highest TPC, TFC, FRAP, and DPPH scavenging capacity of all five teas. Although white tea is also produced from $C$. sinensis, it had significantly lower $(\mathrm{P} \leq 0.05) \mathrm{TPC}, \mathrm{TFC}$, FRAP, and DPPH radical scavenging capacity. Chamomile and berry teas had significantly lower $(P \leq$ 0.05) phenolic and antioxidant contents than green, black, and white teas. Black tea had the highest caffeine content, followed by green, then white tea. Changes in the phenolic content and antioxidant capacity of teas were modelled using zero, first, and FCFO kinetic models. FCFO model fitted the data, with the highest $\mathrm{R}^{2}$ values and lowest MSE values for all teas. This data may be used to optimise industrial and domestic brewing processes for maximum phytochemical preservation. The optimum infusion time for maximum extraction of phenolic and antioxidant compounds for all teas was 
Table 1. Kinetic parameter mean estimates $(k)$, corresponding coefficient of determination $\left(\mathrm{R}^{2}\right)$, and mean square error (MSE) of phenolic content and antioxidant capacity increase in teas after $10 \mathrm{~min}$ infusion

\begin{tabular}{|c|c|c|c|c|c|c|c|}
\hline & & & & & Tea Type & & \\
\hline & & & Black & Green & White & Chamomile & Berry \\
\hline & & $k$ & 36.88 & 46.67 & 13.62 & 5.06 & 5.06 \\
\hline & Zero Order & $\mathrm{R}^{2}$ & 86.68 & 77.74 & 85.80 & 85.00 & 87.01 \\
\hline & & MSE & 2445.14 & 7497.15 & 359.05 & 59.46 & 93.56 \\
\hline & & $k$ & 0.08 & 0.08 & 0.07 & 0.07 & 0.07 \\
\hline Total phenolic & First Order & $\mathrm{R}^{2}$ & 79.80 & 79.94 & 78.70 & 80.75 & 83.46 \\
\hline & & MSE & 3709.98 & 5335.20 & 538.66 & 75.43 & 119.06 \\
\hline & Fractional & $k$ & 0.27 & 0.20 & 0.28 & 0.14 & 0.20 \\
\hline & Conversion First & $\mathrm{R}^{2}$ & 97.02 & 91.21 & 97.61 & 88.05 & 93.80 \\
\hline & Order & MSE & 618.90 & 2663.89 & 68.24 & 54.17 & 47.57 \\
\hline & & $k$ & 1.70 & 2.53 & 0.69 & 0.21 & 0.42 \\
\hline & Zero Order & $\mathrm{R}^{2}$ & 55.83 & 76.43 & 70.56 & 86.77 & 64.75 \\
\hline & & MSE & 26.60 & 22.23 & 2.35 & 0.23 & 1.03 \\
\hline & & $k$ & 0.06 & 0.07 & 0.07 & 0.09 & 0.06 \\
\hline $\begin{array}{l}\text { Total flavonoid } \\
\text { content }\end{array}$ & First Order & $\mathrm{R}^{2}$ & 49.78 & 71.67 & 62.31 & 86.34 & 59.27 \\
\hline & & MSE & 30.25 & 27.20 & 2.97 & 0.24 & 1.21 \\
\hline & Fractional & $k$ & 0.73 & 0.32 & 0.53 & 0.01 & 0.49 \\
\hline & Conversion First & $\mathrm{R}^{2}$ & 91.49 & 86.38 & 97.17 & 86.16 & 82.77 \\
\hline & Order & MSE & 5.77 & 13.57 & 0.26 & 0.27 & 0.57 \\
\hline & & $k$ & 13.79 & 83.82 & 18.80 & 5.94 & 11.79 \\
\hline & Zero Order & $\mathrm{R}^{2}$ & 52.91 & 78.12 & 68.14 & 88.70 & 71.28 \\
\hline & & MSE & 1981.24 & 24639.17 & 1893.43 & 50.27 & 613.45 \\
\hline & & $k$ & 0.07 & 0.09 & 0.15 & 0.19 & 0.19 \\
\hline FRAP & First Order & $\mathrm{R}^{2}$ & 45.65 & 69.21 & 56.37 & 65.90 & 51.77 \\
\hline & & MSE & 2287.20 & 32333.30 & 2611.99 & 144.21 & 858.05 \\
\hline & Fractional & $k$ & 1.16 & 0.43 & 0.29 & 0.10 & 0.35 \\
\hline & Conversion First & $\mathrm{R}^{2}$ & 98.12 & 95.22 & 77.49 & 94.07 & 83.10 \\
\hline & Order & MSE & 90.36 & 5477.91 & 1510.09 & 33.05 & 337.59 \\
\hline & & $k$ & 28.62 & 28.19 & 18.03 & 2.84 & 3.50 \\
\hline & Zero Order & $\mathrm{R}^{2}$ & 57.83 & 45.46 & 62.10 & 88.97 & 55.59 \\
\hline & & MSE & 7070.44 & 11079.80 & 2451.49 & 12.10 & 115.92 \\
\hline & & $k$ & 0.04 & 0.03 & 0.05 & 0.07 & 0.05 \\
\hline $\begin{array}{l}\text { DPPH radical } \\
\text { scavenging capacity }\end{array}$ & First Order & $\mathrm{R}^{2}$ & 53.24 & 43.14 & 57.42 & 84.14 & 51.32 \\
\hline & & MSE & 7841.50 & 11564.23 & 2657.02 & 17.43 & 128.77 \\
\hline & Fractional & $k$ & 0.68 & 1.76 & 0.81 & 0.19 & 0.84 \\
\hline & Conversion First & $\mathrm{R}^{2}$ & 93.68 & 94.12 & 93.21 & 94.26 & 85.71 \\
\hline & Order & MSE & 1173.04 & 1292.82 & 496.04 & 6.80 & 36.73 \\
\hline
\end{tabular}

determined to be 5 mins, as no significant increase in phytochemical content occurred after this time. Green and black tea are a significant source of dietary antioxidants having a greater TPC than fresh orange juice; while green, black and white teas had 7.93, 5.57, and 4.14 times greater DPPH radical scavenging capacity, respectively, than fresh apple juice; and 8.9, 6.2 , and 2.9 times greater scavenging capacity than fresh orange juice.

\section{Conflicts of interest}

The authors certify that they have no affiliations with or involvement in any organisation or entity with any financial interest (such as honoraria; educational grants; participation in speakers' bureaus; membership, employment, consultancies, stock ownership, or other equity interest; and expert testimony or patent-licensing arrangements), or non-financial interest (such as personal or professional relationships, affiliations, knowledge or 
beliefs) in the subject matter or materials discussed in this manuscript.

\section{References}

Achoribo, E.S., Achel, D., Gibrilla, A., Adaboro, M. and Palm, L. (2012). Evaluation of total flavonoid, and total phenolic contents of dried calyx preparations of Bissap (Hibiscus sabdariffa). Elixir Pharmacy, 45, 7660-7663.

Ahmad, M., Baba, W.N., Gani, A., Wani, T.A., Gani, A. and Masoodi, F.A. (2015). Effect of extraction time on antioxidants and bioactive volatile components of green tea (Camellia sinensis), using GC/MS. Cogent Food and Agriculture, 1(1), 1106387. doi:10.1080/23311932.2015.1106387.

Ali, B.H., Wabel, N.A. and Blunden, G. (2005). Phytochemical, pharmacological and toxicological aspects of Hibiscus sabdariffa L.: a review. Phytotherapy Research, 19(5), 369-375.

Andlauer, W. and Héritier, J. (2011). Rapid electrochemical screening of antioxidant capacity (RESAC) of selected tea samples. Food Chemistry, 125(4), 1517-1520.

Anissi, J., El Hassouni, M., Ouardaoui, A. and Sendide, K. (2014). A comparative study of the antioxidant scavenging activity of green tea, black tea and coffee extracts: A kinetic approach. Food Chemistry, 150, 438-447.

Astill, C., Birch, M.R., Dacombe, C., Humphrey, P.G. and Martin, P.T. (2001). Factors affecting the caffeine and polyphenol contents of black and green tea infusions. Journal of Agricultural and Food Chemistry, 49(11), 5340-5347.

Astorino, T., Alkadhi, K. and Preedy, V.R. (2012). Caffeine: Chemistry, analysis, function and effects. Vol 2. Cambridge: Royal Society of Chemistry.

Bagchi, D., Sen, C.K., Bagchi, M. and Atalay, M. (2004). Anti-angiogenic, antioxidant, and anticarcinogenic properties of a novel anthocyanin-rich berry extract formula. Biochemistry (Moscow), 69 (1), 75-80.

Benzie, I.F. and Strain, J. (1996). The ferric reducing ability of plasma (FRAP) as a measure of "antioxidant power": the FRAP assay. Analytical Biochemistry, 239(1), 70-76.

Benzie, I.F. and Szeto, Y. (1999). Total antioxidant capacity of teas by the ferric reducing/antioxidant power assay. Journal of Agricultural and Food Chemistry, 47(2), 633-636.
Blois, M.S. (1958). Antioxidant determinations by the use of a stable free radical. Nature, 181, 1199-1200.

Brown, A. (2014). Understanding food: principles and preparation. Stamford: Nelson Education.

Caballero, B., Finglas, P. and Toldrá, F. (2015). Encyclopedia of Food and Health. $3^{\text {rd }}$ ed. Oxford: Academic Press.

Carloni, P., Tiano, L., Padella, L., Bacchetti, T., Customu, C., Kay, A. and Damiani, E. (2013). Antioxidant activity of white, green and black tea obtained from the same tea cultivar. Food Research International, 53(2), 900-908.

Chin, J.M., Merves, M.L., Goldberger, B.A., SampsonCone, A. and Cone, E.J. (2008). Caffeine content of brewed teas. Journal of Analytical Toxicology, 32(8), 702-704.

Chu, D.C. and Juneja, L.R. (1997). General chemical composition of green tea and its infusion. Chemistry and applications of green tea. Boca Raton: CRC Press.

Cuervo, A., Hevia, A., López, P., Suárez, A., Sánchez, B., Margolles, A. and González, S. (2015). Association of polyphenols from oranges and apples with specific intestinal microorganisms in systemic Lupus erythematosus patients. Nutrients, 7(2), 13011317.

Dai, J. and Mumper, R.J. (2010). Plant phenolics: extraction, analysis and their antioxidant and anticancer properties. Molecules, 15(10), 7313-7352.

Duke, J.A. (1997). The green pharmacy: New discoveries in herbal remedies for common diseases and conditions from the world's foremost authority on healing herbs. Emmaus: Rodale Press.

Duthie, S.J. (2007). Berry phytochemicals, genomic stability and cancer: evidence for chemoprotection at several stages in the carcinogenic process. Molecular Nutrition and Food Research, 51(6), 665-674.

Fernando, C.D. and Soysa, P. (2015). Extraction kinetics of phytochemicals and antioxidant activity during black tea (Camellia sinensis L.) brewing. Nutrition Journal, 14(1), 74.

Guimarães, R., Barros, L., Dueñas, M., Calhelha, R.C., Carvalho, A.M., Santos-Buelga, C., Queiroz, M.J.R.P. and Ferreira, I.C.F.R. (2013). Nutrients, phytochemicals and bioactivity of wild Roman chamomile: a comparison between the herb and its preparations. Food Chemistry, 136(2), 718-725.

Haghi, A.H., Safaei, A. and Mehran, M.G. (2013). Analysis of phenolic compounds in Matricaria 
chamomilla and its extracts by UPLC-UV. Research in Pharmaceutical Sciences, 9(1), 31-37.

Ho, C.-T., Lin, J.-K. and Shahidi, F. (2008). Tea and tea products: chemistry and health-promoting properties. Boca Raton: CRC Press.

Hui, Y.H. and Evranuz, E.Ö. (2015). Handbook of vegetable preservation and processing. Boca Raton: CRC Press.

Igile, G.O., Oleszek, W., Jurzysta, M., Burda, S., Fafunso, M. and Fasanmade, A.A. (1994). Luteolin is more potent than butylated hydroxytoluene (BTH). Journal of Agricultural and Food Chemistry, 42, 2445-2448.

Imran, A., Butt, M.S., Sharif, M.K. and Sultan, J.I. 2013 Chemical profiling of black tea polyphenols. Pakistan Journal of Nutrition, 12(3), 261-267

Jaiswal, A.K., Gupta, S. and Abu-Ghannam, N. 2012. Kinetic evaluation of colour, texture, polyphenols and antioxidant capacity of Irish York cabbage after blanching treatment. Food Chemistry, 131(1), 63-72.

Jaiswal, A.K., Rajauria, G., Abu-Ghannam, N. and Gupta, S. (2012). Effect of different solvents on polyphenolic content, antioxidant capacity and antibacterial activity of Irish York cabbage. Journal of Food Biochemistry, 36(3), 344-358.

Juneja, L.R., Kapoor, M.P., Okubo, T. and Rao, T. (2013). Green tea polyphenols: nutraceuticals of modern life. Boca Raton: CRC Press.

Jung, Y.D. and Ellis, L.M. (2001). Inhibition of tumour invasion and angiogenesis by epigallocatechin gallate (EGCG), a major component of green tea. International Journal of Experimental Pathology, 82 (6), 309-316.

Karori, S., Wachira, F., Wanyoko, J. and Ngure, R. (2007). Antioxidant capacity of different types of tea products. African Journal of Biotechnology, 6(19), 2287-2296.

Kaur, C. and Kapoor, H.C. (2001). Antioxidants in fruits and vegetables the millennium's health. International Journal of Food Science and Technology, 36, 703-725.

Komes, D., Horžić, D., Belščak, A., Ganić, K.K. and Vulić, I. (2010). Green tea preparation and its influence on the content of bioactive compounds. Food Research International, 43(1), 167-176.

Langley-Evans, S.C. (2000). Antioxidant potential of green and black tea determined using the ferric reducing power (FRAP) assay. International Journal of Food Sciences and Nutrition, 51(3), 181-188.
Lee, J.-E., Lee, B.-J., Chung, J.-O., Kim, H.-N., Kim, E.H., Jung, S., Lee, H., Lee, S.-J. and Hong, Y.-S. (2015). Metabolomic unveiling of a diverse range of green tea (Camellia sinensis) metabolites dependent on geography. Food Chemistry, 174, 452-459.

Oh, J., Jo, H., Cho, A.R., Kim, S.-J. and Han, J. (2013). Antioxidant and antimicrobial activities of various leafy herbal teas. Food Control, 31(2), 403-409. doi:http://dx.doi.org/10.1016/

j.foodcont.2012.10.021.

Paganga, G., Miller, N. and Rice-Evans, C.A. (1999). The polyphenolic content of fruit and vegetables and their antioxidant activities. What does a serving constitute? Free Radical Research, 30(2), 153-162.

Panda, H. (2011). The complete book on cultivation and manufacture of tea. Delhi: Asia Pacific Business Press Inc.

Pandey, K.B. and Rizvi, S.I. (2009). Plant polyphenols as dietary antioxidants in human health and disease. Oxidative Medicine and Cellular Longevity, 2(5), 270-278.

Pellegrini, N., Serafini, M., Colombi, B., Del Rio, D., Salvatore, S., Bianch,i M. and Brighenti, F. (2003). Total antioxidant capacity of plant foods, beverages and oils consumed in Italy assessed by three different in vitro assays. The Journal of Nutrition, 133(9), 2812-2819.

Petronilho, S., Maraschin, M., Coimbra, M.A. and Rocha, S.M. (2012). In vitro and in vivo studies of natural products: A challenge for their valuation. The case study of chamomile (Matricaria recutita L.). Industrial Crops and Products, 40, 1-12.

Preedy, V.R. (2012). Tea in health and disease prevention. Oxford: Academic Press.

Preedy, V.R. (2014). Processing and impact on antioxidants in beverages. Oxford: Academic Press.

Prior, R.L. and Cao, G. (1999). Antioxidant capacity and polyphenolic components of teas: implications for altering in vivo antioxidant status. Proceedings of the Society for Experimental Biology and Medicine, 220 (4), 255-261.

Rajauria, G., Jaiswal, A.K., Abu-Ghannam, N. and Gupta, S. (2013). Antimicrobial, antioxidant and free radical-scavenging capacity of brown seaweed Himanthalia elongata from western coast of Ireland. Journal of Food Biochemistry, 37(3), 322-335.

Ramadan-Hassanien, M.F. (2008). Total antioxidant potential of juices, beverages and hot drinks consumed in Egypt screened by DPPH in vitro assay. Grasas y Aceites, 59(3), 254-259. 
Rao, M.A., Rizvi, S.S.H., Datta, A.K. and Ahmed, J. (2014). Engineering properties of foods. Boca Raton: CRC Press.

Rusak, G., Komes, D., Likić, S., Horžić, D. and Kovač, M. (2008). Phenolic content and antioxidative capacity of green and white tea extracts depending on extraction conditions and the solvent used. Food Chemistry 110(4), 852-858.

Saberi, H. (2010). Tea: a global history. London: Reaktion Books.

Samaniego-Sánchez, C., Inurreta-Salinas, Y., QuesadaGranados, J.J., Blanca-Herrera, R., Villalón-Mir, M., de la Serrana, H.L.-G. and Martínez, M.C.L. (2011). The influence of domestic culinary processes on the Trolox Equivalent Antioxidant Capacity of green tea infusions. Journal of Food Composition and Analysis, 24(1), 79-86.

Sáyago-Ayerdi, S.G., Arranz, S., Serrano, J. and Goñi, I. (2007). Dietary fiber content and associated antioxidant compounds in roselle flower (Hibiscus sabdariffa L.) beverage. Journal of Agricultural and Food Chemistry, 55(19), 7886-7890.

Sazegar, M., Banakar, A., Bahrami, N., Bahrami, A., Baghbani, M., Nematolahi, P. and Mottaghi, M. (2011). Determination of the antioxidant activity and stability of Chamomile (Matricaria chamomilla L.) extract in sunflower oil. World Applied Sciences Journal, 12(9), 1500-1504.

Setchell, K.D., Faughnan, M.S., Avades, T., ZimmerNechemias, L., Brown, N.M., Wolfe, B.E., Brashear, W.T., Desai, P., Oldfield, M.F. and Botting, N.P. (2003). Comparing the pharmacokinetics of daidzein and genistein with the use of 13C-labeled tracers in premenopausal women. The American Journal of Clinical Nutrition, 77(2), 411-419.

Soni, U., Brar, S. and Gauttam, V.K. (2015). Effect of seasonal variation on secondary metabolites of medicinal plants. International Journal of Pharmaceutical Sciences and Research, 6(9), 36543652

Unachukwu, U.J., Ahmed, S., Kavalier, A., Lyles, J.T. and Kennelly, E.J. (2010). White and green teas (Camellia sinensis var. sinensis): variation in phenolic, methylxanthine, and antioxidant profiles. Journal of Food Science, 75(6), C541-548. doi:10.1111/j.1750-3841.2010.01705.x.

World Health Organization (WHO). (2015). Practical Advice on Maintaining a Healthy Diet. Retrieved May 9, 2016 from World Health Organization
Website:

http://www.who.int/mediacentre/ factsheets/fs394/en/

Yang, J.-G., Liu, B.-G., Liang, G.-Z. and Ning, Z.-X. (2008). Structure-activity relationship of flavonoids active against lard oil oxidation based on quantum chemical analysis. Molecules, 14(1), 46-52.

Yang, J. and Liu, R.H. (2013). The phenolic profiles and antioxidant activity in different types of tea. International Journal of Food Science and Technology, 48(1), 163-171.

Yoo, K.M., Lee, C.H., Lee, H., Moon, B. and Lee, C.Y. (2008). Relative antioxidant and cytoprotective activities of common herbs. Food Chemistry, 106(3), 929-936. 